\title{
Surveillance of West Nile Virus Disease, Tel Aviv District, Israel, 2005 to 2010
}

E Kopel (eran.kopel@mail.huji.ac.il)1, Z Amitai ${ }^{1}$, H Bin²,3, L M Shulman ${ }^{3,4}$, E Mendelson,4, R Sheffer

1. Tel Aviv District Health Office, Ministry of Health, Tel Aviv, Israel

2. National Centre for Zoonotic Viruses, Central Virology Laboratory, Ministry of Health, Chaim Sheba Medical Centre, Tel Hashomer, Israel

3. Central Virology Laboratory, Ministry of Health, Chaim Sheba Medical Centre, Tel Hashomer, Israel

4. School of Public Health, Sackler Faculty of Medicine, Tel-Aviv University, Tel Aviv, Israel

Kopel E, Amitai Z, Bin H, Shulman LM, Mendelson E, Sheffer R. Surveillance of West Nile Virus Disease, Tel Aviv District, Israel, 2005 to 2010.

Euro Surveill. 2011;16(25):pii=19894. Available online: http://www.eurosurveillance.org/ViewArticle.aspx?Articleld=19894

We present the findings of a six-year surveillance period (2005-2010) of human West Nile virus (WNV) infection in Tel Aviv district, Israel. Initial notifications of positively identified patients received from the Central Virology Laboratory were followed by epidemiological investigations of the local district health office. During 2005-2010, 104 patients, 79 with WNV neuroinvasive and 25 with WNV non-neuroinvasive disease were reported. The median age of the patients with a neuroinvasive disease was 74 years (range: 15 to 95 years) and 53 of such patients had encephalitis, 14 had acute flaccid paralysis, and 12 had meningitis. The case-fatality rate in these patients was $8 \%$. The average annual incidence of neuroinvasive disease during 2005-2010 was 1.08 per 100,000 population. The incidence declined by $86 \%$ steadily between 2005 and 2009 ( $p$ for trend=0.005), but increased by more than six-fold in 2010 . Elderly ( $\geq 65$ years) men, comprising 25 patients of whom 24 were chronically-ill, had the highest incidence of WNV encephalitis (p<o.001). These findings are concordant with previous data, at the national level, published in Israel and the United States. Notably, the percentage of previously healthy patients, who developed a neuroinvasive disease was the highest $(37 \%, p=0.001)$ in the surveillance period in 2010.

\section{Introduction}

West Nile virus (WNV) is a mosquito-borne arbovirus of the family Flaviviridae. Numerous avian species serve as the amplifying hosts. These include, migratory birds, such as the white storks which travel across Israel each autumn, as well as urban species, such as the common house sparrows. Transmission to humans mainly occurs by mosquito vectors, principally by mosquitoes of the genus Culex, during their active period, usually between mid-summer and early autumn. WNV has rapidly expanded in both the eastern and western hemispheres in the past two decades $[1,2]$.

Human West Nile fever, caused by laboratory-confirmed WNV infection, was reported in Israel for the first time in the early 1950s, with several outbreaks in that decade, and an additional outbreak in 1980 [3]. The largest outbreak (439 serologically-confirmed cases with 29 deaths) of human WNV infection in Israel occurred in 2000 , with a $73 \%$ rate of neuroinvasive disease in hospitalised patients $[3,4]$. Following this outbreak, a national surveillance system was established for humans and mosquitoes [5] and since 2001 WNV infection is notifiable in Israel. The surveillance system detects new cases of human WNV infections and characterises viral genotypes. The system is based on initial notifications of probable or confirmed cases of WNV infection by the Central Virology Laboratory (CVL) and on the subsequent epidemiological investigations of these patients by the local district health offices.

This report summarises a six-year period (2005-2010) of human WNV surveillance in the Tel Aviv district. This most densely populated urban district of Israel included 7,425 residents per square kilometre at the end of 2009, according to the Israel Central Bureau of Statistics [6].

\section{Methods}

\section{Epidemiological investigation}

The Tel Aviv District Health Office routinely receives notifications from the CVL about probable or confirmed cases of WNV infection in patients who are residents of the district. The local health office initiates an epidemiological investigation by collecting available information on the patients and by using a standard national-based questionnaire. For hospitalised patients, information is gathered from the patients' hospital records, and by conducting an interview with the patient or with a close family member, in order to obtain information regarding risk factors for WNV infection such as occupation, residence or travel near water bodies, recent exposure to mosquitoes, migratory birds and domestic fowl. For non-hospitalised patients, another source of information, in addition to the patient's interview, is usually the family physician. 
The gathered demographic, clinical, laboratory and epidemiological data are reported to the Division of Epidemiology, Ministry of Health, Jerusalem.

\section{Laboratory analysis}

During the study period, the CVL used a combination of serology assays comprising in-house synchronised IgMcapture (until August 2007), indirect IgG, and indirect IgG avidity ELISAs [4], and from September 2007, the IgM InBios commercial kit (West Nile Detect IgM Capture ELISA, Seattle, Washington, USA) [7]. Results were interpreted according to the manufacturer's instructions. IgM and IgG tests were conducted simultaneously. The avidity IgG test was performed on single samples with IgM and IgG positive results. Unresolved cases were further tested by virus neutralisation assay [8].

\section{Case definition}

The following official national laboratory criteria of WNV infection are used by the CVL to define probable and confirmed cases.

- A confirmed case is defined as having at least one of the following criteria: (i) Serological conversion or at least two-fold increase in ELISA test results of IgM antibodies and/or IgG antibodies levels [4,7] in blood or in cerebrospinal fluid (CSF), in paired samples taken at least seven days apart; (ii) IgM antibodies level higher than IgG antibodies level and also IgG avidity lower than $30 \%$ in one blood sample; (iii) At least ten-fold higher optical density (OD) of IgM antibodies in CSF in one sample, compared to a reference cut-off level; (iv) Positive result of West Nile viral RNA in CSF, body fluids or body tissues, by real-time RT-PCR assays detecting WNV lineages 1 and 2 [8-10].

- A probable case is defined as detection of WNV IgM antibodies, without detection of IgG antibodies, in one blood or CSF sample or the lack of increase in IgM antibodies, without the presence of IgG antibodies, between paired samples of blood collected one to seven days apart.

The data in this report were summarised and analysed from the district health office's files of individual patients who had an onset of laboratory-confirmed or probable WNV infection, between 1 January 2005 and 31 December 2010. No clinical criteria were used, in addition to the laboratory criteria, for the case definition.

\section{Clinical criteria}

The term 'neuroinvasive disease' as used in our analysis refers to WNV-associated diagnoses of encephalitis, meningoencephalitis, meningitis and acute flaccid paralysis (AFP). The clinical definitions of encephalitis, meningitis and AFP, were adopted from previously described definitions [11]. Patients who have had a combined clinical picture of encephalitis and meningitis, hence, meningoencephalitis, were classified as having encephalitis, as in previous reports $[12,13]$.
Also, any presentation of AFP combined with other illness (i.e. encephalitis) was classified as AFP only [12].

We assumed that in non-neuroinvasive patients, there would be a high level of cohort incompleteness due to lack of serological testing and therefore, lack of WNV diagnosis. These patients largely present with a mild nonspecific illness, which is often not followed by seeking medical care [14]. Thus, this report mainly analyses the cohort of WNV neuroinvasive disease patients who usually require diagnosis and treatment within a hospital setting, and therefore, this cohort is more likely to be complete.

Patients were also classified as to whether they had a pre-existing chronic medical condition, which was further classified as to whether it was an immunocompromised state. Any chronic medical condition, excluding psychiatric conditions, was included.

We abstracted these data, post hoc, at the information summary stage of the study from written medical diagnoses in patients' hospital records, where available.

\section{Statistical analysis}

For the purpose of $p$ value calculations, we used the exact two-tailed Mann-Whitney $U$ test in case of mean age differences, and not the Student's t-test, because of the small sample size. For the same reason, we used two-tailed Fisher's exact test in case of categorical data and Spearman's rank correlation coefficient for the trend of incidence. Also, the chi-square test with Yates' correction was used for testing differences in the average annual incidence between certain subgroups. A two-tailed $p$ value inferior to 0.05 was considered significant. Statistical analyses were performed using SPSS version 15.0 software (Chicago, Illinois, USA).

The annual average population estimates for the years 2005-2009, used as denominators for incidence calculations, were taken from the Israel Central Bureau of Statistics. The annual average population estimate for 2010 was based on an estimated annual population growth rate of $1.725 \%$, which was derived from the average population growth rate during 2005-2009.

\section{Results}

Between 1 January 2005 and 31 December 2010, 104 confirmed or probable cases of WNV infection were reported in the Tel Aviv district. Of these 104 cases, 94 (90\%) had an onset of illness in the period from July to the end of October (Figure 1). Eighteen of the $23(78 \%)$ neuroinvasive and non-neuroinvasive cases in 2010, and 18 of the $25(72 \%)$ cases in 2005 , occurred in July and August, compared to the occurrence of only 16 of the $56(29 \%)$ cases in the years 2006-2009 combined during the same period.

Seventy-nine patients have had a neuroinvasive disease (Table), all of whom were hospitalised: $53(67 \%)$ had encephalitis, 12 (15\%) had meningitis and 14 (18\%) 
had AFP, of whom two patients had Guillain-Barré syndrome. The median age of all patients with a neuroinvasive disease was 74 years (range: 15 to 95 years) and $51(65 \%)$ of these patients were aged 65 years or older. Fourty $(51 \%)$ of these patients were males.

Of 79 patients with neuroinvasive disease, 25 (32\%) were elderly men ( $\geq 65$ years), of whom 24 were chronically-ill. Similarly, 26 (33\%) elderly women including 25 chronically-ill were part of the 79 patients presenting with neuroinvasive disease.

Patients with encephalitis had a significantly higher mean age than patients with meningitis and AFP (74 years; $95 \%$ confidence interval $(\mathrm{Cl}): 70-78$ years vs 59 years; $95 \% \mathrm{Cl}$ : 51-67 years, $\mathrm{p}=0.02)$. The mean age of patients with meningitis was significantly lower than the mean age of patients with encephalitis and AFP ( 47 years; $95 \% \mathrm{Cl}$ : $35-60$ years vs 73 years; $95 \% \mathrm{Cl}: 69-76$ years, p<0.001).

Of all 79 patients with a neuroinvasive disease, 69 $(87 \%)$ had a pre-existing chronic medical condition.

\section{FIGURE 1}

Human West Nile virus infection confirmed and probable cases, by month of illness onset, 2005-2010, Tel Aviv

district, Israel $(\mathrm{n}=104)$

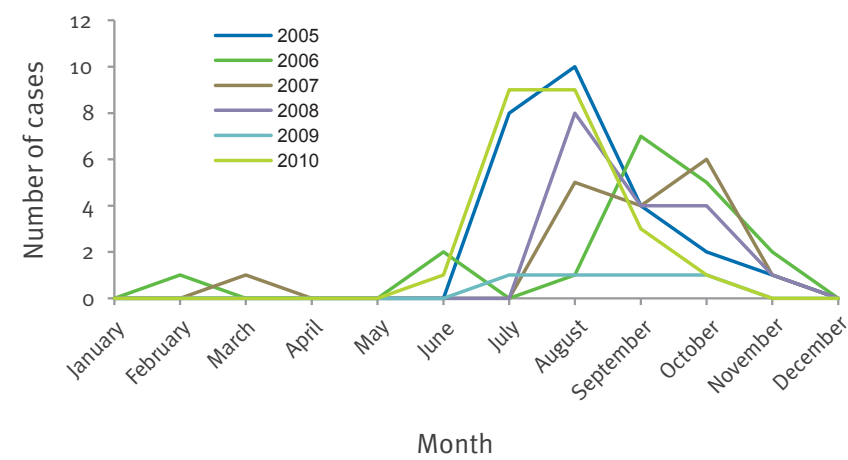

Human West Nile virus infection confirmed and probable cases include 79 cases of neuroinvasive disease and 25 cases of nonneuroinvasive disease.
The group of patients with meningitis had a significantly lower percentage of chronic illness when compared to the group of patients with encephalitis (8/12, 67\%; $95 \% \mathrm{Cl}: 35 \%-90 \%$ vs 49/53, 92\%; $95 \%$ $\mathrm{Cl}: 82 \%-98 \%$, respectively, $\mathrm{p}=0.03)$. The percentage of patients with a pre-existing chronic medical condition was significantly lower in 2010 , when compared to the period between 2005 and 2009 (12/19, 63\%; 95\% Cl: $38 \%-84 \%$ vs 57/60, $95 \%$; $95 \% \mathrm{Cl}: 86 \%-99 \%$, $\mathrm{p}=0.001)$.

The case-fatality rate (CFR) of patients with a neuroinvasive disease was six of $79(8 \%)$. The patients who died were older than 74 years of age, five of six were females, five of six had a pre-existing chronic medical condition, and four of six had a diagnosis of WNV encephalitis.

During the surveillance period, the annual percentage of patients with encephalitis, meningitis or AFP ranged between $55 \%$ and $90 \%, 0 \%$ and $25 \%$, and, $10 \%$ and $33 \%$, respectively (Figure 2 ).

\section{FIGURE 2}

Percentage of patients with West Nile virus neuroinvasive disease, by year and clinical diagnosis, Tel Aviv district, Israel, 2005-2010 ( $\mathrm{n}=79)$

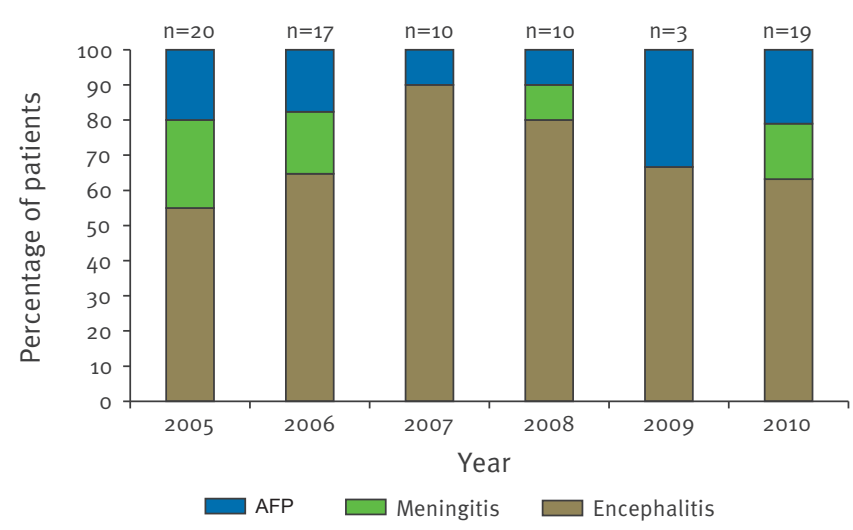

AFP: acute flaccid paralysis.

\section{TABLE}

Characteristics of cases of human West Nile virus neuroinvasive disease by clinical diagnosis, Tel Aviv district, Israel, 2005-2010 (n=79)

\begin{tabular}{|c|c|c|c|c|}
\hline Characteristic & Encephalitis & Meningitis & AFP & Total \\
\hline & $(n=53)$ & $(n=12)$ & $(n=14)$ & $(n=79)$ \\
\hline Median age, years (range) & $75(38-95)$ & $45(15-79)$ & $77(41-95)$ & $74(15-95)$ \\
\hline Male sex (\%) & $26(49)$ & $6(50)$ & $8(57)$ & $40(51)$ \\
\hline Deaths (\%) & $4(8)$ & $1(8)$ & $1(7)$ & $6(8)$ \\
\hline Immunocompromised (\%) & $5(9)$ & o (o) & $1(7)$ & $6(8)$ \\
\hline Any chronic medical condition ${ }^{a}(\%)$ & $49(92)$ & $8(67)$ & $12(86)$ & $69(87)$ \\
\hline
\end{tabular}

AFP: acute flaccid paralysis.

a Most commonly included was a history of one or more illnesses such as essential hypertension, hyperlipidemia, and/or diabetes mellitus. 
The average annual incidence of neuroinvasive disease between 2005 and 2010 was 1.08 per 100,000 population (Figure 3). The incidence of neuroinvasive disease declined significantly, between 2005 and 2009, from 1.69 to 0.24 per 100,000 population (an $86 \%$ decrease, $r s=-0.97, p$ for trend=0.005), but increased more than six-fold in 2010 , to 1.47 per 100,000 population, compared to the previous year. The change in trend, during 2005-2010, of the WNV-associated central nervous system diagnoses (encephalitis and meningitis) was similar to the trend of the WNV-associated peripheral nervous system illness (AFP).

The average annual incidence of neuroinvasive disease, by age, between 2005 and 2010 (Figure 4) demonstrated a peak in incidence among patients aged 75 years or older (7.03 per 100,000 population), while no patients aged less than 15 years were reported. The peak of the average annual incidence of encephalitis and of AFP was in patients aged 75 years or older

\section{FIGURE 3}

Annual incidence of human West Nile virus neuroinvasive disease by year and clinical diagnosis, Tel Aviv district, Israel, 2005-2010

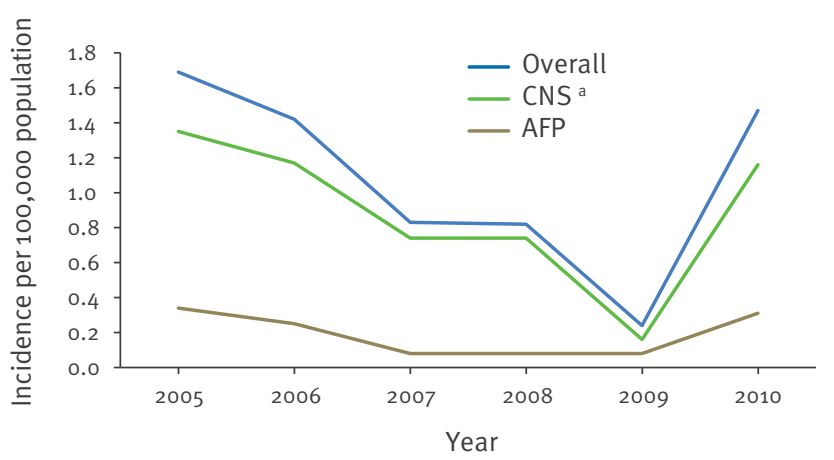

AFP: acute flaccid paralysis; CNS: central nervous system group of diagnoses.

a The CNS group of diagnoses includes encephalitis and meningitis.

\section{FIGURE 4}

Average annual incidence of human West Nile virus neuroinvasive disease by age group, Tel Aviv district, Israel, 2005-2010

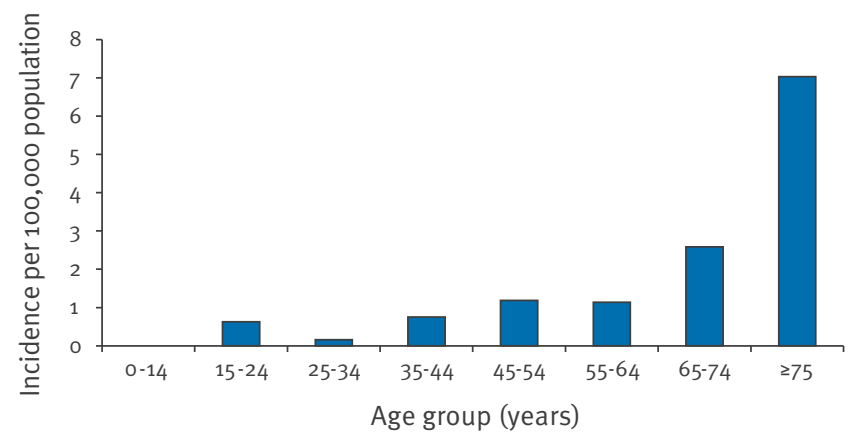

Average annual incidence is calculated using Israel Central Bureau of Statistics average population estimates of Tel Aviv district for 2008.
(5.18 and 1.48 per 100,000 population, respectively) (Figure 5).

The average annual incidence of neuroinvasive disease had a similar pattern among men and women (Figure 6) with the exception that the incidence in male patients aged 65-74 years, was almost three-fold higher than in female patients of the same age group (4.11 per 100,000 population vs 1.41 per 100,000 population, respectively). The latter difference could not be confirmed with statistical significance, but this could be due to the small number of cases in each of the male and female subgroups.

During the surveillance period, elderly men ( $\geq 65$ years) had the highest average annual incidence of WNV encephalitis in the cohort, and it was significantly higher than the rest of the patients with encephalitis, aged between 35 and 64 years (4.54 per 100,000 population vs 1.19 per 100,000 population, p<0.001).

\section{FIGURE 5}

Average annual incidence of human West Nile virus neuroinvasive disease by age group and clinical diagnosis, Tel Aviv district, Israel, 2005-2010

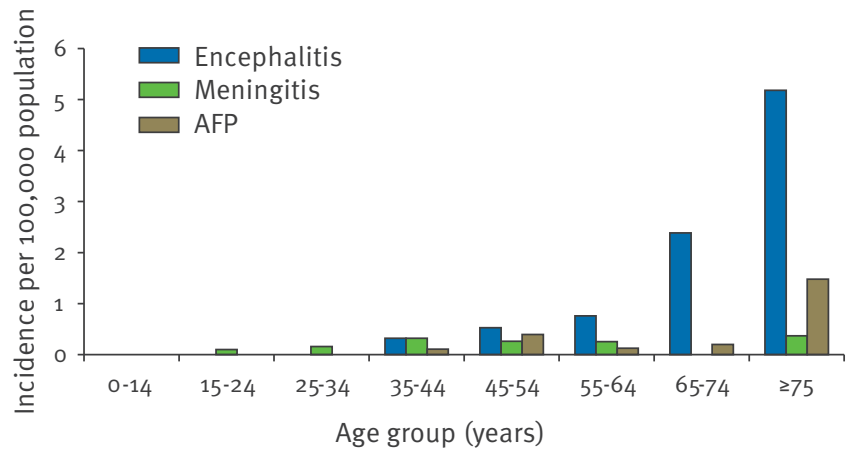

AFP: acute flaccid paralysis.

Average annual incidence is calculated using Israel Central Bureau of Statistics average population estimates of Tel Aviv district for 2008.

\section{FIGURE 6}

Average annual incidence of human West Nile virus neuroinvasive disease by age group and sex, Tel Aviv district, Israel, 2005-2010

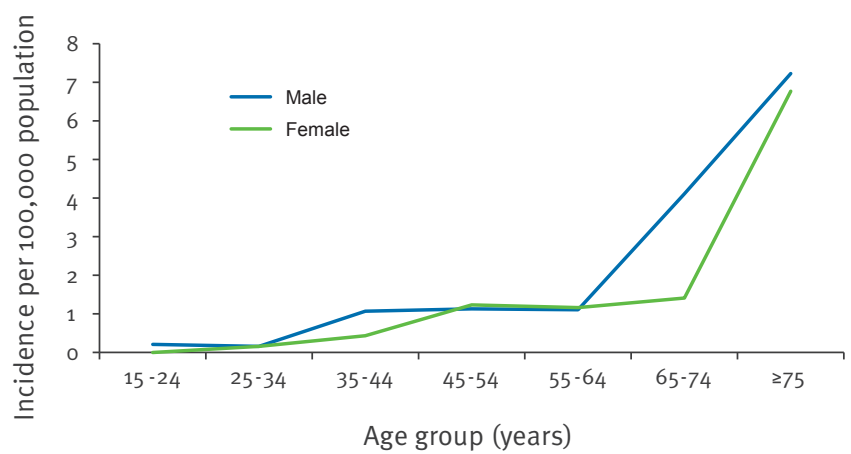

Average annual incidence is calculated using Israel Central Bureau of Statistics average population estimates of Tel Aviv district for 2008. 
Similarly, male patients aged 75 years or older had the highest average annual incidence of encephalitis or AFP in the cohort during the surveillance period, which was significantly higher than the rest of the patients, aged between 35 and 74 years, with encephalitis (5.42 per 100,000 population vs 1.46 per 100,000 population, p<0.001) or AFP (1.81 per 100,000 population and 0.33 per 100,000 population, $\mathrm{p}=0.004$ ). In contrast, female patients aged 75 years or older had the highest average annual incidence of meningitis, but it was not significantly higher than the rest of the patients with meningitis, aged between 15 and 74 years ( 0.62 per 100,000 population vs 0.17 per 100,000 population, $\mathrm{p}=0.3)$.

\section{Discussion}

The data that were summarised and analysed in this study reflect a six-year period of WNV surveillance in Tel Aviv district. After several years of successive declines in WNV neuroinvasive disease, its incidence increased sharply in 2010.

We observed, as previously reported by Lindsey et al. [12], a higher incidence of encephalitis in elderly male patients during our surveillance period. These patients were also chronically ill, which may serve as an independent risk factor for WNV neuroinvasive disease [15]. However, five of the six fatalities in the observation period were female patients.

Two-thirds of the patients with a neuroinvasive disease had encephalitis $(53 / 79,67 \%)$, followed by patients with AFP $(14 / 79,18 \%)$. Of those latter 14 patients with AFP, four were diagnosed in 2010 alone. WNVassociated AFP was hardly observed during the large outbreak of 2000 in Israel: $98 \%$ of 233 hospitalised patients were diagnosed as having West Nile fever, encephalitis or meningitis but not AFP, which was reported as myelitis by Chowers et al. [13].

In our series, patients with meningitis were significantly younger than patients with other forms of neuroinvasive disease. This age discrepancy was described previously by Lindsey et al. [12].

Our reported CFR for the patients with neuroinvasive disease $(6 / 79,8 \%)$, who were all hospitalised, was similar to the overall CFR in Israel during the outbreak in $2000(29 / 439,7 \%)$ [4]. The CFR in our study was however half the CFR of hospitalised patients (33/233, $14 \%)$, for whom data were obtained in 2000 [13]. Our reported CFR was also similar to that in the United States (US), which was $9 \%$ of the patients with a neuroinvasive disease during 1999-2008, most of whom were hospitalised [12].

Remarkably, the highest percentage of WNV neuroinvasive disease occurring in previously healthy patients was observed in 2010, when compared to the period between 2005 and $2009(7 / 19,37 \%$ vs $3 / 60,5 \%$, $\mathrm{p}=0.001$ ).
In our series, meningitis affected patients who were significantly younger on average than patients with other forms of neuroinvasive disease. The year 2010 did not appear to present an exception, although the total number of cases was small (39 years on average $(n=3)$ for patients with meningitis vs 47 years in all years of the surveillance period $(n=12))$. Because of their younger age, patients with WNV meningitis would be less likely to have underlying medical conditions. Therefore, we examined whether the overall increase of previously healthy patients presenting with WNV neuroinvasive disease in 2010 could have been due to an increase in the number of patients with WNV meningitis in that year; however, of the patients with a neuroinvasive disease in 2010, only three of 19 had meningitis, which was well within the range of annually reported cases of WNV meningitis in the district, between 2005 and 2009 (o/10 in 2007 and o/3 in 2009 up to $5 / 20$ in 2005).

We also verified if the number of previously healthy patients presenting with a neuroinvasive disease had increased in other years than 2010, such as in 2005 , in which a peak in the proportion of meningitis was observed (5/20). There was, however, no lower proportion of chronically-ill patients $(17 / 20)$ in that year.

Additionally, to our knowledge, there was no change in the surveillance practice over the study time period that could account for the highest percentage of previously healthy patients presenting with WNV neuroinvasive disease observed in 2010.

In the years following the major national outbreak of WNV infection in 2000 , various strains of WNV lineage 1 predominated in Israel either in isolated foci or in the entire country [16]. Representative Israeli WNV genomic sequences of viruses isolated from mosquitoes and humans between 2000 and 2009 were deposited in the GenBank/EMBL/DDBJ database under accession numbers GU246634-GU246714 and HM152773-HM152780, respectively.

The emergence of new viral genotypes simultaneously with higher number of human cases was observed in Israel in 2000, 2005, and 2007 [16]. Particularly, in 2005, an increased nationwide WNV activity, with 102 laboratory-confirmed human patients [16] of whom $20 \%$ were from the Tel Aviv district, which was a part of the epicentre, was reported [17]. Molecular analysis of human and mosquito isolates revealed a genotype most similar to the one that was isolated in the equine WNV outbreak in Morocco in 2003 [18], and which had not been isolated previously from humans or mosquitoes in Israel [17].

Notably, 2005 and 2010 shared some epidemiological similarities, as we observed in the district: both years had a similar incidence of WNV neuroinvasive disease, higher than the other years of surveillance, including a higher incidence of AFP, which is a long-term 
complication of considerable morbidity and mortality $[19,20]$. In addition, the majority of WNV infection cases in both years had occurred early, already in July and August, compared to later months of occurrence, in the other years.

One possible explanation to the increased incidence of morbidity observed in 2010, which was also accompanied by a higher fraction than before of previously healthy patients could be the recent emergence of another WNV strain or variant, as in 2005. A genotype characterisation of the 2010 WNV strain is however not available to date.

Another explanation for the 2010 epidemiological characteristics could be the early arrival of an extremely hot summer, already in May. This might have contributed to the early peak of WNV season in 2010, in the district. The period of May-July 2010 was warmer than the perennial average of the years 1981-2000 [21-23]. In addition, August 2010 was the warmest measured month in Israel $[24,25]$.

The summer of 2010 was extremely hot also in areas, which usually have a temperate climate, such as northern Greece and Romania. A human WNV outbreak emerged in northern Greece for the first time, early in July 2010 [26]. An additional noticeable outbreak, which also began in early July 2010, was reported in Romania, where a neuroinvasive lineage 2 WNV strain was detected for the first time [27]. Whether there is a possible association between recent climatic extremes in the region, WNV activity, and its mosquito vectors should be extensively studied.

\section{Conclusions}

We report on the epidemiological and clinical characteristics of human WNV infection in the Tel Aviv district between 2005 and 2010. As such, it may be limited in time, place and person. Nevertheless, our main body of findings, such as the patients' characteristics, was concordant with previous data, at the national level, published in Israel and the US.

Any successful WNV surveillance system should integrate and maintain both epidemiological and laboratory capabilities for prolonged periods of time, particularly in endemic and densely populated areas, such as the Tel Aviv district.

\section{Acknowledgements:}

We thank Anat Scheffer and Sofia Katser for conducting numerous epidemiological investigations along the years.

\section{References}

1. Petersen LR, Marfin AA, Gubler DJ. West Nile virus. JAMA. 2003;290(4):524-8
2. Malkinson M, Banet C, Weisman Y, Pokamunski S, King $R$, Drouet $M$, et al. Introduction of West Nile virus in the Middle East by migrating white storks. Emerg Infect Dis. 2002;8(4):392-7.

3. Weinberger M, Pitlik SD, Gandacu D, Lang R, Nassar F, Ben David D, et al. West Nile fever outbreak, Israel, 2000: epidemiologic aspects. Emerg Infect Dis. 2001;7(4):686-91.

4. Bin H, Grossman Z, Pokamunski S, Malkinson M, Weiss L, Duvdevani P, et al. West Nile fever in Israel 1999-2000: from geese to humans. Ann N Y Acad Sci. 2001;951:127-42.

5. Orshan L, Bin H, Schnur H, Kaufman A, Valinsky A, Shulman $\mathrm{L}$, et al. Mosquito vectors of West Nile Fever in Israel. J Med Entomol. 2008;45(5):939-47.

6. Israel Central Bureau of Statistics. Statistical Abstract of Israel 2010-No.61. 2010. [Accessed 29 December 2010]. Available from: http://www.cbs.gov.il/reader/shnatonenew_site.htm.

7. Welch RJ, Anderson BL, Litwin CM. Evaluation of a new commercial enzyme immunoassay for the detection of IgM antibodies to West Nile virus using a ratio method to eliminate nonspecific reactivity. J Clin Lab Anal. 2008;22(5):362-6.

8. Hindiyeh M, Shulman LM, Mendelson E, Weiss L, Grossman Z, Bin $\mathrm{H}$. Isolation and characterization of West Nile virus from the blood of viremic patients during the 2000 outbreak in Israel. Emerg Infect Dis. 2001;7(4):748-50.

9. Lanciotti RS, Kerst AJ, Nasci RS, Godsey MS, Mitchell CJ, Savage HM, et al. Rapid detection of west nile virus from human clinical specimens, field-collected mosquitoes, and avian samples by a TaqMan reverse transcriptase-PCR assay. J Clin Microbiol. 2000;38(11):4066-71.

10. Linke S, Ellerbrok H, Niedrig M, Nitsche A, Pauli G. Detection of West Nile virus lineages 1 and 2 by real-time PCR. J Virol Methods. 2007;146(1-2):355-8

11. Sejvar J,, Haddad MB, Tierney BC, Campbell GL, Marfin AA, Van Gerpen JA, et al. Neurologic manifestations and outcome of West Nile virus infection. JAMA. 2003;290(4):511-5.

12. Lindsey NP, Staples JE, Lehman JA, Fischer M; Centers for Disease Control and Prevention (CDC). Surveillance for human West Nile virus disease - United States, 1999-2008. MMWR Surveill Summ. 2010;59(2):1-17.

13. Chowers MY, Lang R, Nassar F, Ben-David D, Giladi M, Rubinshtein $\mathrm{E}$, et al. Clinical characteristics of the West Nile fever outbreak, Israel, 2000. Emerg Infect Dis. 2001;7(4):675-8.

14. Zou S, Foster GA, Dodd RY, Petersen LR, Stramer SL. West Nile fever characteristics among viremic persons identified through blood donor screening. J Infect Dis. 2010;202(9):1354-61.

15. Jean CM, Honarmand S, Louie JK, Glaser CA. Risk factors for West Nile virusneuroinvasive disease, California, 2005. Emerg Infect Dis. 2007;13(12):1918-20.

16. Bin H, Shulman L, Hindiyeh M, Weiss L, Schlezinger S, Orshan L, et al. Clinical and molecular aspects of West Nile virus infections in Israel from 2000 to 2008 . The 9th Tel Aviv University Research Fair; 2010 Mar 25; Tel Aviv, Israel. Available from: http://medicine.tau.ac.il/fair-abstracts/ uploads/Z35.doc.

17. Bin H, Shulman L, Weiss L, Schlezinger S, Kaufman Z, Orshan $\mathrm{L}$, et al. WNF resurgence in Israel in 2005 was associated with introduction of new WNV genotypes and high rate of mosquito infections. The Second Jerusalem Symposium on ArthropodBorne Viral Diseases; 2006 Jun 25-30; Mitzpe Haymim, Israel.

18. Schuffenecker I, Peyrefitte CN, el Harrak M, Murri S, Leblond A, Zeller HG. West Nile virus in Morocco, 2003. Emerg Infect Dis. 2005;11(2):306-9.

19. Saad M, Youssef S, Kirschke D, Shubair M, Haddadin D, Myers J, et al. Acute flaccid paralysis: the spectrum of a newly recognized complication of West Nile virus infection. J Infect. 2005;51(2):120-7.

20. Sejvar JJ, Bode AV, Marfin AA, Campbell GL, Pape J, Biggerstaff BJ, et al. West Nile Virus-associated flaccid paralysis outcome. Emerg Infect Dis. 2006;12(3):514-6.

21. Israel Meteorological Service. Monthly summary of weather - May 2010. Israel Meteorological Service. [Accessed 1 September 2010]. Hebrew. Available from: http://www.ims.gov. $\mathrm{il} / \mathrm{NR} /$ rdonlyres/A61ACC44-DE6D-4F5F-90F6-7CF3CC978CC2/o/ may10.pdf.

22. Israel Meteorological Service. Monthly summary of weather - June 2010. Israel Meteorological Service. [Accessed 1 September 2010]. Hebrew. Available from: http://www.ims.gov. il/NR/rdonlyres/E6150B31-B8DA-462D-9EFC-28F45B4FBB94/o/ june10.pdf. 
23. Israel Meteorological Service. Monthly summary of weather - July 2010. Israel Meteorological Service. [Accessed 1

September 2010]. Hebrew. Available from: http://www.ims.gov. il/NR/rdonlyres/A732F141-D50D-4A95-A4A3-70D62EC423C7/o/ july2010.pdf.

24. Israel Meteorological Service. Monthly summary of weather - August 2010. Israel Meteorological Service. [Accessed 1 September 2010]. Hebrew. Available from: http://www.ims.gov. il/NR/rdonlyres/59992847-D836-49DF-B8D7-2D62F7892555/o/ aug10.pdf.

25. Zafrir R. It's official: Last month marked Israel's hottest August. Haaretz. 1 September 2010. Available from: http:// www.haaretz.com/news/national/it-s-official-last-monthmarked-israel-s-hottest-august-1.311546.

26. Papa A, Danis K, Baka A, Bakas A, Dougas G, Lytras T, et al. Ongoing outbreak of West Nile virus infections in humans in Greece, July - August 2010. Euro Surveill. 2010;15(34):pii=19644. Available from: http://www. eurosurveillance.org/ViewArticle.aspx?Articleld=19644.

27. Sirbu A, Ceianu CS, Panculescu-Gatej RI, Vázquez A, Tenorio A, Rebreanu R, et al. Outbreak of West Nile virus infection in humans, Romania, July to October 2010. Euro Surveill. 2011;16(2):pii=19762. Available from: http://www. eurosurveillance.org/ViewArticle.aspx?Articleld=19762. 